deceased died a natural death, but that his death may Jiave been accelerated by certain herbs improperly administered to him, and which, in the opinion of many medical gentlemen were opposed to the cure of the disease under which he was labouring, and they condemn the reckless and inconsiderate use of such materials, without a regular and proper attendance on the deceased." The Coroner said, " that the jury had taken a very merciful view of the case, which he would bear in mind, and in case any death in future occurred under simlar circumstances, where it could be shown clearly to arise from an improper administration of a medicine, he should advise a verdict of manslaughter." The newspapers in different parts of the country have already recorded so many instances of death following the use of the deleterious drug recommended by Coffin, and exhibited most rashly and ignorantly by uneducated impostors, that it is quite time that Government should interfere. Quacks destroy more lives than actual warfare. Printers, journeyman shoemakers, bricklayers, labourers, \&cc., who purchase Coffin's quackeries and his pamphlet, fancy they have found a royal road to medicine, and practise accordingly.-Medical Times.

\section{THE CENSUS OF 1851.}

In the general instructions issued by the Registrar. General, with the return to be made for taking the census of the population in 1851, we find the following notification:- "Members of the medical profession to state the university, college, or hall, of which they are graduates, fellows, or licentiates-also whether they practise as physicians, surgeons, or general practitioners. or are "not practising.'" This will prove an important and efficient mode of ascertaining the number of legally qualified practitioners in this country. The table will also, by this means, exhibit the relative number of the different classes of the profession. We regret to observe that the word "apothecary" has been omitted; we hope, even now, that it will be introduced. There are many apothecaries who practise as such in London, and who do not practise as surgeons, and who therefore cannot be correctly styled general practitioners. Lancet.

\section{ROYAL COLLEGE OF SURGEONS.}

Gentlemen admitted Members on Friday, November 29th, 1850 :- Rabert Batty, Liverpool; Andrew Muskett Blomfield, Barton Bendish, Norfolk ; George Alfred Galland, Leeds; Adam Hampson, Bolton-leMoors, Lancashire; Willam Dickenson Lacy, Newark, Nottinghamshire; Henry Lawrence, Bath; Edward Humphrey Paget, Leicester; John Ringland, Belfast.

\section{SOCIETY OF APOTHECARIES.}

Gentlemen admitted Members on Thursday, Novem. ber 21st, 1850 :-Edward Adolphus Brown, Chelmsford; Joseph Wilson Beamont, Sheffield, York; James Stoate, Bristol ; Thomas Young Thompson, Sherburn.

Gentlemen admitted Members on Thursday, November 28th, 1850 :-William Frederick Bassett; Mark Rowland Day, Oxford ; George Frederick Gwyn, LongStratton, Norfolk; Charles William Hammond, Ipswich.

\section{OBITUARY.}

November 11th, at Demarara, John M'Lagan, M.D. November 12th, by suicide, John George Simes, late surgeon at Hungerford, aged 33.
November 22nd, at 72, Upper Berkeley Street, Portman Square, Dr. John Taylor, late surgeon in the army, in the 80th year of his age.

BOOKS RECEIVED FOR REVIEW.

Address to a Medical Student. Second edition. Oxford : Parker. London: Churchill. 1850. 12mo.

The Profession of Medicine: its Study, Practice, Duties, and Rewards. An Address delivered at St. Bartholomew's Hospital. By Charles West, M.D. London: Longmans and Co. 1850.

Identity or Non-Identity of the Specific Cause of Typhoid, Typhus, and Relapsing Fevers. By W. Jenner, M.D. (Reprint.)

Report of the Proceedings of the Pathological Society of London. Fourth Session. 1849-50.

Notice of an Unpublished MS. of Harvey. By Dr. Paget.

\section{PROVINCIAL MEDICAL AND SURGICAL ASSOCIATION.}

\section{NOTICE TO MEM BERS.}

Gentlemen who have not yet paid their subscriptions for the current year, or who are in arrears, are requested to forward the amount due either to the Secretary of the district in which they reside, or to the Treasurer or Secretary of the Association at Worcester.

The attention of Members is particularly requested $\varnothing$ to the following resolution, unanimously agreed to at the late Anniversary Meeting, held at Hull on the 7 th and 8th of August, 1850 :-

"But if any Member's subscription remain unpaid twelve months after it shall become due, the Medical Journal, and other publications of the Society, shall be withheld from such Member till his arrears be paid; and when any Member has been in arrears of subscription for the space of three years, application shall be made for the same by the General Secretary, and if the arrears be not paid in three months the name of that Member shall be omitted from the list of Subscribers; but the omission shall not de deemed, either in honour or equity, as releasing any gentleman from the subscription owing during his Membership."

JAMES P. SHEPPARD. Secretary.

Worcester, Sept. 17th, 1850.

\section{ERRATA.}

In our number for November 13, p. 519, we have inadvertently substituted the words "puerperal fever" for " danger" and "death" in childbed.

In Mr. Berry's " Case of Sudden Death seven hours after delivery, \&c," in the second line, for June 16th, 1830 , read June 16th, " 1850 ."

\section{TO CORRESPONDENTS.}

Communications have been received from $\mathrm{Mr}$. Prichard, Mr. Cooksey, Mr. White, Mr. Growse, Dr. Duncan.

It is requested that all letters and communications connected with the Editorial department be sent to J. H. Walsh, Esq., Foregate Street, Worcester. Parcels and books for review may be addressed to the care of Mr. Churchill, Princes Street, Soho. 